\title{
The loess slope stability study
}

\author{
Xu Shi-qiang ${ }^{1,2}$, Zhao Tao $^{2}$ \\ (1.School of science, Chang'an University, xi'an 710064, shaanxi, China; \\ 2.School of highway, Chang'an University, xi'an 710064, shaanxi, China)
}

Keywords: loess slope; circular arc method; the rate of top surface slope

\begin{abstract}
We often use circular arc method when calculating the stability of the slope. But this kind of method ignores how the slope rate of top influences stability of slope. In this thesis, a destruction model of loess slope is set up to study the regular rule of how the slope rate of top influences stability of slope, which will have great guiding significance in the construction of slopes in highway engineering.
\end{abstract}

With the rapid development of economy in China, the northwest loess region has become the important area in energy development and construction of China. When roads are built in the loess area, it is inevitable that there will appear a lot of cutting slope. Especially in recent years with the implementation of the western economic development policy, a lot of high cutting slopes which are taller than $30 \mathrm{~m}$ are met in the construction of high-grade highways in loess region of north Shaanxi, and there are a lot of accidents caused by instability of slope under sliding. According to the survey, instability of slopes including natural ones, railway, highway and open-air mine often happens in rainy season, especially under heavy rains, and there will be a lot of phenomenon such as landslide, collapse and instability of slope, which often cost a lot.

The mechanics model of circular arc method is simple, and the quantitative evaluation index can be got, i.e. safety coefficient, which can be accepted easily. In practical calculation, what slope rate of surface influences the stability of slope is ignored in circular arc method, and the potential sliding surface cannot be sure. Therefore, in this paper, destruction model of loess slope is established according to the actual situation of loess slope with consideration of slope rate of surface so that a program which analyzes stability of slope is made to solve the problem.

\section{Calculation model}

The damage of loess slope includes damage of surface and damage of body damage. The main form of slope damage is collapse. Through the investigation of slope damage typically in Shaanxi, Gansu, Shanxi, it is found that vertical fracture and circular arc accord with damage model of loess area. Additionally, loess high slope is often combined with old slopes and new ones, and the damage form of slope is combined with vertical fracture, a straight line and circular arc. The height of circular arc with cutting point of upper line increases as the slope increases. Under ordinary 
circumstances, the range of height of the cutting point is $(1 / 3 \sim 2 / 3) \mathrm{H}, \mathrm{H}$ is height of slope. Therefore, this article establishes a model as follows:

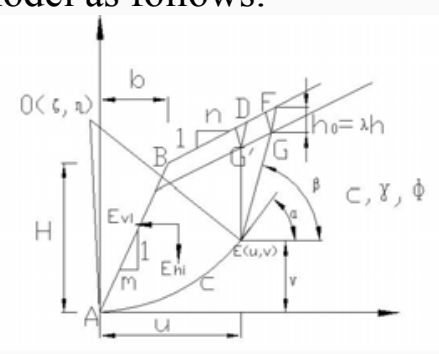

Figure 1 The cross section of loess high slope and the form of the most dangerous sliding surface

\section{Analysis of examples}

\section{Brief introduction of this project}

This loess high slope is excavated from a side of the mountain. Figure 3 is the cross-sectional designing picture of excavation cut slope. The height of slope is $37.0 \mathrm{~m}$, and a platform width of $2.0 \mathrm{~m}$ is set $20.0 \mathrm{~m}$ above the foot of slope. From the top of the slope, the soil of this slope can be divided into 2 kinds of different properties. The first layer is Q3 loess, which is yellowish-brown and the thickness is about $22.0 \mathrm{~m}$. The second layer is Q2 loess, and the thickness is $15.0 \mathrm{~m}$. Bulk density is $\gamma=18.0 \mathrm{KN} / \mathrm{m}^{3}, c=100 \mathrm{KPa}, \varphi=30^{\circ}$.

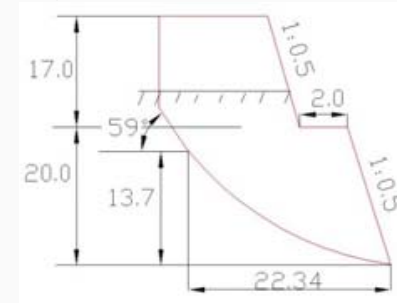

Figure 1 The cross section of loess high slope and the form of the most dangerous sliding surface

In this paper, one of the features of this calculation method is to calculate safety coefficient of slope surface under different slope rates. In table 1-1, according to this method, the results that how the safety coefficient changes with the change of slope rate of surface ${ }^{m}$ and slope rate of top ${ }^{n}$ are given, which can be seen in figure 1-3.

The results how the safety coefficient changes as the slope rate of surface and the slope rate of top change

\begin{tabular}{|c|c|c|c|c|c|c|c|c|}
\hline \multirow[b]{2}{*}{$\begin{array}{l}\text { Slope } \\
\text { types }\end{array}$} & \multirow[b]{2}{*}{$\begin{array}{l}\text { slope rates } \\
m\end{array}$} & \multirow{2}{*}{$\begin{array}{l}\text { The } \\
\text { calculation } \\
\text { results } \\
\text { according } \\
\text { this method }\end{array}$} & \multicolumn{6}{|c|}{ slope rate of top $n$} \\
\hline & & & 1 & 2 & 4 & 10 & 100 & $\infty$ \\
\hline \multirow{11}{*}{ 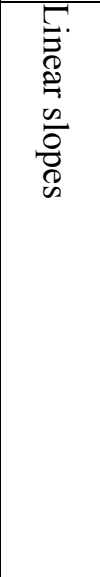 } & \multirow{6}{*}{0.4} & Kmin & 0.83 & 1.05 & 1.11 & 1.14 & 1.15 & 1.15 \\
\hline & & $\mathrm{u}(\mathrm{m})$ & 90.00 & 12.72 & 12.72 & 12.72 & 12.72 & 12.72 \\
\hline & & $\mathrm{v}(\mathrm{m})$ & 11.12 & 6.32 & 6.94 & 7.59 & 7.56 & 7.56 \\
\hline & & $\mathrm{R}(\mathrm{m})$ & 64.41 & 12.83 & 13.17 & 14.31 & 13.49 & 13.49 \\
\hline & & $\left(\alpha^{\circ}\right)$ & 52 & 60 & 62 & 62 & 64 & 64 \\
\hline & & $\left(\beta^{\circ}\right)$ & 50 & 59 & 61 & 61 & 62 & 62 \\
\hline & \multirow{5}{*}{0.6} & Kmin & 0.84 & 1.28 & 1.37 & 1.41 & 1.43 & 1.43 \\
\hline & & $\mathrm{u}(\mathrm{m})$ & 90.00 & 18.72 & 18.72 & 18.72 & 18.72 & 18.72 \\
\hline & & $\mathrm{v}(\mathrm{m})$ & 10.70 & 6.32 & 7.64 & 8.28 & 8.94 & 8.93 \\
\hline & & $\mathrm{R}(\mathrm{m})$ & 63.89 & 16.28 & 17.28 & 18.24 & 18.32 & 18.32 \\
\hline & & $\left(\alpha^{\circ}\right)$ & 52 & 56 & 58 & 58 & 60 & 60 \\
\hline
\end{tabular}




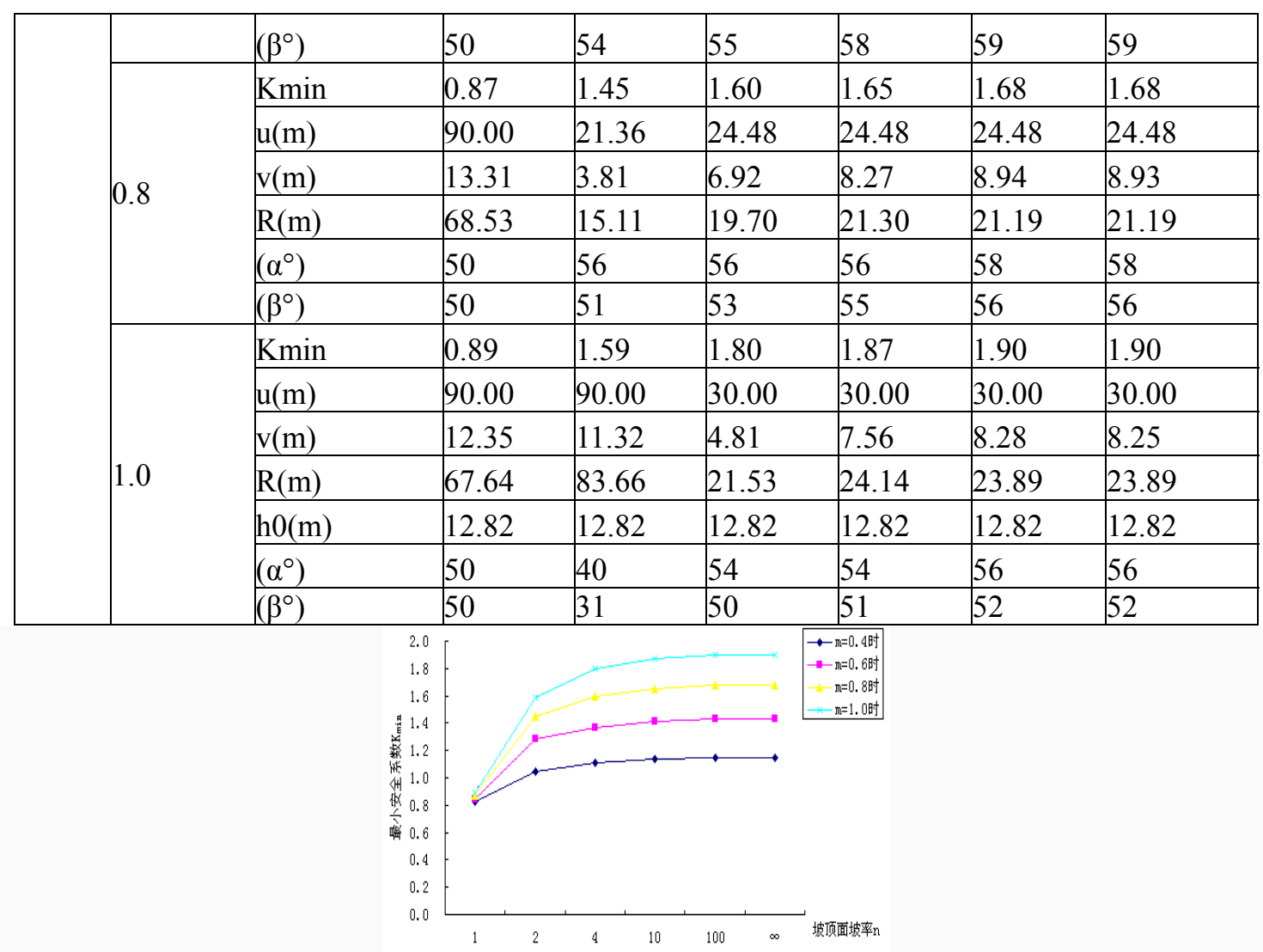

Figure 1-3 How the safety coefficient changes with the change of slope rate of top

From table 1-1 and figure 1-3, it can be seen as follows:

1. The safety coefficient increases as the slope rate of top ${ }^{n}$ increases, so it is advantageous to the stability of slope when the top of the slope is horizontal.

2. When the slope rate of top ${ }^{n}$ is greater than 4 , the safety coefficient changes little as the slope rate of top changes. When the slope rate of top is greater than or equals to 10 , it is nearly the same as the top of the slope is horizontal.

3. When the slope rate of top is small( $n=1)$, it influences safety coefficient greatly, and along with the increase of slope rate of surface, the influence will be greater.

\section{Conclusion}

The damage mechanism and stability evaluation of loess slope is a very complex problem. The traditional circular sliding method ignores how the slope rate of top influences stability of slope, which there will be a lot of potential safety problems. Therefore, in this paper, how the slope rate of top influences stability of slope is studied. It can be seen that when the slope rate of top is greater than 4, the safety coefficient changes little with the change of the slope rate of top. When the slope rate of top is greater than or equals to 10 , it is nearly the same to that when the top of the slope is horizontal. Therefore, in the construction of slope, there is no need in flatting the top of the slope. As long as a certain value is reached, the construction cost will be saved to a great degree.

\section{References}

[1] Luo Ming-Hong, Tang Hui-Ming, Rigid limit equilibrium method considering seismic force and it's application[J].Chinese Journal of Rock Mechanics and Engineering, (in Chinese)

[2] Wang FangRong, seismic forces of slope stability of rock mass drift angleinfection [J]. sichuan power design institute, (in Chinese)

[3] Zhuang Le-He, considering the force of the earthquake slope slide the calculation of 
possibility [J], China university of geosciences, (in Chinese))

[4] Liu HongShuai, Bo JingShan, Liu DeDong. Review on study of seismic stability analysis of rock-soil slopes[J], Earthquake Engineering and Engineering,2005.25(1). （in Chinese )

[5] Yin Zi Hong,Analysis on the Stability of Superhighway Landslide in Earthquakes[J],Journal of Chongqing Institute of Technology(Natural Science Edition,2007, 21 (9))

[6] Chen NianYing Zeng DunDi. on the vertical seismic force and seismic damage[J]. Chengdu University (Natural Science Edition), 1998, 17 (2): 47 - 50.( in Chinese)

[7] Ministry of Communications standards, Seismic Design of Highway Engineering (JTJ004 89) [S]. People's Communications Press, 1994: 104. 